\title{
Operation mechanism design Of China Electricity Market
}

\author{
Dezhi Li ${ }^{1, a}$, Yuting Liu ${ }^{2, b}$ \\ ${ }^{1}$ China Electric Power Research institute, Beijing, 100192, China; \\ ${ }^{2}$ North China Electric Power University, Beijing, 102206, China. \\ aldz97@126.com, bxiaoxi618@qq.com
}

Keywords: electric power system reform; operating mechanism; mechanism design.

\begin{abstract}
The State Council issued "Some opinions on further deepening the reform of the electric power system". China's electricity sales side reform has entered a new chapter. The operating mechanism of the electricity market is also different from the previous model. This paper introduces the cultivation mechanism of the main body of the market, the cultivation mechanism of the user side, the access mechanism, the information sharing mechanism and the mechanism of information disclosure. This paper also points out the incompleteness of the reform of China's electricity sales side. This paper summarizes the current operating mechanism, and provides reference for future development.
\end{abstract}

\section{Introduction}

After the opening of the electricity sales side, the experience of foreign sale of electricity has an important reference for China's reform. The subject of foreign electricity sales side in "the experience and enlightenment of international electricity sales side market opening" is analyzed in [1]. This paper studied about electricity market access mechanism, trading mechanism, replacement of electricity supplier mechanism and credit mechanism and so on. The historical process of China's power system reform is reviewed in [2]. This paper analyzed the current situation in China to promote the reform of the electricity side of the difficulties. The reform of the electricity sales side in the reform of the electric power system in the "the system design and suggestion of promoting the marketization of electricity sales side in China" are analyzed in [3-5].

\section{The operation mechanism of China power sale market}

\subsection{The cultivation mechanism of the main body of the market}

Currently, besides electricity sales company of the power grid enterprises, there are four ways to cultivate the emerging electricity supplier. First, encourage developed high-tech industrial park or other areas with more concentrated load to build more distribution network, then set up the electricity sales company. Secondly, encourage the power supply enterprises and Industrial users with industrial distribution networks turn into the electricity sales company. In the same time, allow them to develop freely and expand the power supply area. Then, encourage the integration of electricity retail, water supply, gas supply, heating (cold) services and set up the new utility company. Finally, encourage distributed power / micro grid system combined with other capital, power generation companies and users to set up electricity sales company.

\subsection{User side training mechanism}

The experience of the construction of the electricity market in foreign countries shows that the construction of the electricity market which is full of competition and vitality can not only cultivate the market main body, the user side is also cannot be ignored. It is necessary for users to choose and participate actively in the sale of electricity. China's existing power consumption system has been relatively cured for many years, users (especially ordinary residents) for the habit of electricity consumption patterns have been formed. Only by cultivating the market awareness of power users, breaking the inertia of electricity consumption, the user can really participate in the sale of electricity market. 


\subsection{Access mechanism of electricity sales company}

The new reform pointed out that the establishment of market access and exit mechanism, requiring scientific definition of technology, safety, environmental protection, energy saving requirements of the social responsibility of the main electricity supplier access conditions. The electricity companies need to be registered in accordance with the company law, with independent legal personality, engaged in the sale of electricity with the corresponding total assets. They also need to have the scale and business scope of the sale of equipment to adapt to the business premises, as well as the relevant full-time professionals. Qualified electricity companies should be put on record by the provincial government or the department which is authorized by the provincial government.

\subsection{Information sharing mechanism}

Electricity sales side reform will form a diversified electricity supplier. But the installing, metering, meter-reading and other services will still be responsible for the traditional Power Grid Corp or emerging distribution company. In such a market structure, Power Grid Corp or emerging distribution companies will grasp the first-hand data and information. For the relatively independent trading center, electricity data is needed for transaction settlement of the electricity side. For the sale of electricity, the user's electricity data is not only the inevitable need for settlement, but also important material to improve the quality of service, innovative service mechanism.

\subsection{Information disclosure mechanism}

In electricity-sale market, although diversified electricity sellers are facing fierce market competition environment, there are possibilities of making use of the information asymmetry between electricity users (especially ordinary residential users) and themselves to damage the benefit of users. Even though the users have the right to change the electricity sellers and the channels of complaining to electricity regulation department, they still have to suffer the loss due to conversion cost and poor quality of service. Therefore, in order to encourage electricity sellers to compete healthily by improving the quality of service and restrain electricity sellers of making use of the information asymmetry to damage the benefit of users, I suggest the electricity regulation department to build fair and transparent electricity-sale regulation and information disclosure system.

\section{Operating system guarantee of China's electricity market}

(1) The new reform identified the development direction of the electricity sale side reform: On the one hand, ensure the direction of the marketization. Gradually open the sale of electricity to social capital. Cultivate the main body of electricity market by multi-channels. On the other hand, ensure the direction of safe, efficient, clean, low-carbon energy, play the role of market orientation.

(2) Determine the responsibility and cultivate a diversified sale of electricity to protect the power universal service. Power grid enterprises undertake the power supply base of power supply service, to ensure that residents, agriculture, public utilities and public services such as electricity. Electricity supplier should also undertake some responsibility.

(3) Set condition. The administrative examination and approval don't need to establish, but the mechanism of subject entry and exit should establish. If the main body of the market violates the relevant laws, regulations of the state, market rules and bankrupt, these companies must be forced to withdraw from the market. These companies will be blacklisted and not allowed to enter the market.

(4) The main body of the market is flexible, and play the role of market price discovery. In No.9 Document, the market trading mode is defined, the main market players can be bilateral transactions and can also focus on trading through the trading center. In order to prevent risks arising from the transaction, the establishment of information disclosure and credit evaluation mechanism, strengthen risk prevention and supervision are also mentioned.

\section{Conclusion}

(1) Combine with existing policies, gradually guide the reform, so as to synchronize with other tasks. Electricity sales side liberalization is not an isolated reform, which is closely related to the 
transmission and distribution price, electricity consumption plan liberalization, the construction of the electricity market reform tasks.

(2) Protect the user option. The core of the sale of electricity side release is the user choose the sale of electricity subject freely. Users need to fully understand the mode of sale. The government should cooperate with the sale of electricity companies to cultivate users.

(3) Cultivate the main body of selling electricity. In reference to the experience of foreign sales of electricity, while taking into account the early release of China's electricity sales side, regulatory mechanisms, credit system is not perfect. In order to fully protect the quality of customer service, should be subject to the sale of electricity on the economic scale, technical qualifications, credit level, experience and other access conditions to make clear requirements. At the same time, we should also take into account the national energy-saving industrial policy and environmental policy requirements, then gradually cultivate the main market of electricity sales.

\section{References}

[1] Zhang Xiaoxuan, Xue Song. The international experience and Enlightenment of the electricity market liberalization [J], Automation of Electric Power Systems, 2016,(5):23-26.

[2] Bao Qiang, Wang Xiaowen. Research on the development direction of electricity sales in the market competition environment [J]. Power Demand Side Management, 2015 (4): 48-51

[3] Scherer, P. Chinese promote electricity sales side of the market design and suggestion system [J]. Automation of Electric Power Systems, 2015, 39 (14):32-35.

[4] Zhu Rui. Study on the construction of competitive electricity market in China [D]. Chengdu: Southwestern University of Finance and Economics, 2010.

[5] Lai Youwei. The reform of China's power system is facing problems and the regulatory system of the [J]. Industrial Economy, 2012, (10):12-16. 